\title{
Rapid One-Step Detection of Viral Particles Using Aptamer-Based Thermophoretic Assay
}

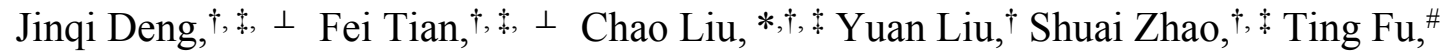
Jiashu Sun*,†,

$\dagger$ Beijing Engineering Research Center for BioNanotechnology, CAS Key Laboratory of Standardization and Measurement for Nanotechnology, CAS Center for Excellence in Nanoscience, National Center for Nanoscience and Technology, Beijing 100190, China.

+ Sino-Danish College, Sino-Danish Center for Education and Research, University of Chinese Academy of Sciences, Beijing 100049, China.

\# Institute of Cancer and Basic Medicine (ICBM), Chinese Academy of Sciences, The Cancer Hospital of the University of Chinese Academy of Sciences, Hangzhou, Zhejiang 310018, China.

" State Key Laboratory of Chemo/Bio- Sensing and Chemometrics, College of Chemistry and Chemical Engineering, Aptamer Engineering Center of Hunan Province, Hunan University, Changsha, Hunan 410082, China.

Email:

*Weihong Tan: tan@hnu.edu.cn

* Jiashu Sun: sunjs@nanoctr.cn

*Chao Liu: liuc@nanoctr.cn 
Materials. Pseudotyped SARS-CoV-2 particles (PSV, $3 \times 10^{4} \mathrm{TU} \mu \mathrm{L}^{-1}$; TU, transducing units) and lentivirus (Len, $10^{5} \mathrm{TU} \mu \mathrm{L}^{-1}$ ) were from Fubio biological Technology Co., Ltd. (China). PSV displaying SARS-CoV-2 spike protein has been used extensively as models for viral pathogens. PSV was encapsulated with the RNA genome containing GFP gene driven by a CMV promotor, and its intact function and activity were verified by the effective infection of ACE2-expressing cells. ${ }^{\text {S1-2 }}$ Rhodamine B and polyethylene glycol (PEG8000, molecular weight: 8000 Da) were from Aladdin Biochemical Technology Co., Ltd. (China). Rhodamine B-PEG8000 was from Beijing Solarbio Science \& Technology Co., Ltd. (China). DNA oligonucleotides were from Sangon Biotech (China). DiI (ex/em: 550/567 nm) was from ThermoFisher (USA). $\mathrm{MgCl}_{2}$ was from Sigma-Aldrich (USA). Phosphate buffered saline (PBS) was from Gibco (USA). ELISA kit for spike antigen was purchased from Sino Biological Inc. (kit40591, Beijing, China).

Annealing of the DNA probes. DNA oligonucleotides were dissolved in the buffer $(0.55 \mathrm{mM} \mathrm{MgCl} 2$ in PBS) with the final concentration of $10 \mu \mathrm{M}$. The solution was heated at $95{ }^{\circ} \mathrm{C}$ for $5 \mathrm{~min}$ and then immediately cooled at ice for $5 \mathrm{~min}$. The DNA probes were stored at $-20^{\circ} \mathrm{C}$ until usage.

Measurement of $\boldsymbol{S}_{\boldsymbol{T}}$ for PEG8000. The $S_{T}$ of the PEG8000 was determined according to the equation:

$$
c / c_{0}=\exp \left[-S_{T}\left(T-T_{0}\right)\right]
$$


where $c$ and $c_{0}$ represent the concentration of PEG8000 at local and far away from the laser, and $T$ and $T_{0}$ are the temperatures at local and far away from the laser. The irradiation-induced temperature distribution in a $15-\mu \mathrm{m}$-high chamber was mapped based on the fluorescence intensity of temperature sensitive Rhodamine B (0.1 $\mathrm{mM}$ in $20 \mathrm{mM}$ carbonate buffer solution) under $15 \mathrm{~mW}$ laser irradiation (1480 $\mathrm{nm})$. The concentration distribution of PEG8000 caused by laser irradiation was profiled using Rhodamine B-PEG8000 (6 \% in $20 \mathrm{mM}$ carbonate buffer solution) based on the fluorescence intensity after $30 \mathrm{~s}$ irradiation. The $S_{T}$ of PEG8000 was determined to be $0.04 \mathrm{~K}^{-1}$, through the linear relationship between the $\log$ of relative concentration of PEG8000 $\left(\ln \left(c_{0} / c\right)\right)$ and temperature rise $\left(\Delta T=T-T_{0}\right)$.

Numerical simulation of thermophoretic accumulation of viral particles. The coupled solutions of flow field, heat transfer, PEG8000 transportation, and virus transportation were solved by a finite element method as follows:

$$
\begin{aligned}
& \nabla \cdot(\rho \mathbf{u})=0 \\
& \frac{\partial(\rho \mathbf{u})}{\partial t}+\nabla \cdot(\rho \mathbf{u u})=-\nabla p+\nabla \cdot(\eta \nabla \mathbf{u})-\rho g \alpha \Delta T \\
& \frac{\partial(\rho T)}{\partial t}+\nabla \cdot(\rho \mathbf{u} T)=\nabla \cdot\left(\frac{\lambda}{c_{\mathrm{p}}} \nabla T\right)+S \\
& \frac{\partial c_{P E G}}{\partial t}+\nabla \cdot\left(\mathbf{u} c_{P E G}\right)=\nabla \cdot\left(-D_{P E G} \nabla c_{P E G}-S_{T}^{P E G} D_{P E G} c_{P E G} \nabla T\right) \\
& \frac{\partial c_{\text {Virus }}}{\partial t}+\nabla \cdot\left(\mathbf{u} c_{\text {Virus }}\right)=\nabla \cdot\left\{-D_{\text {Virus }} \nabla c_{\text {Virus }}-\left[S_{T}^{\text {Virus }}-2 \pi\left(S_{T}^{P E G}-\frac{1}{T}\right) a \delta^{2} c_{P E G}^{0}\right] D_{\text {Virus }} c_{\text {Virus }} \nabla T\right\}
\end{aligned}
$$

where $\mathbf{u}$ is the flow velocity vector, $\rho$ is the fluid density, $p$ is the pressure, $\eta$ is the dynamic viscosity, $c_{P E G}$ is the PEG8000 concentration, $S_{T}^{P E G}=0.04 \mathrm{~K}^{-1}$ is the Soret coefficient of PEG8000, $D_{P E G}=9.3 \times 10^{-11} \mathrm{~m}^{2} \mathrm{~s}^{-1}$ is the diffusion 
coefficient of PEG8000, $c_{\text {Virus }}$ is the virus concentration, $D_{\text {Virus }}=4.5 \times 10^{-12} \mathrm{~m}^{2} \mathrm{~s}^{-1}$ is the diffusion coefficient of viral particles, $a$ is the virus radius, $\delta \approx 6 \mathrm{~nm}$ is the length scale of depletion interaction between virus and PEG8000, and $c_{P E G}^{0}$ is the PEG8000 concentration far from laser spot. All governing equations were solved by a finite element solver (Comsol 4.4, Femlab). For the $1480 \mathrm{~nm}$ laser, the power was $15 \mathrm{~mW}$, the diameter of focused spot was $10 \mu \mathrm{m}$, and the attenuation length in water was $400 \mu \mathrm{m}$. Gravity force was applied to the fluid motion to allow the thermal convection induced by the thermal expansion of water. The expansion rate $\alpha$ can be derived from the fluid density $\rho$ that was piecewise linear determined by three points of $1000 \mathrm{~kg} \mathrm{~m}^{-3}$ at $4{ }^{\circ} \mathrm{C}, 988 \mathrm{~kg} \mathrm{~m}^{-3}$ at $50{ }^{\circ} \mathrm{C}$, and $958 \mathrm{~kg}$ $\mathrm{m}^{-3}$ at $100{ }^{\circ} \mathrm{C}$. The thermal conductivity $\lambda$ of water, glass, and sapphire were 0.6 , 1.3 , and $35 \mathrm{~W} \mathrm{~m}^{-1} \mathrm{~K}^{-1}$, respectively. The heat capacity $c_{\mathrm{p}}$ of water, glass, and sapphire were 4200,761 , and $755 \mathrm{~J} \mathrm{Kg}^{-1} \mathrm{~K}^{-1}$, respectively.

PEG concentration gradient. Under a sharp temperature gradient $(\nabla T)$ created at the center of the microchamber $(80-\mu \mathrm{m}$ high) through localized heating using an infrared laser (1480 nm, $15 \mathrm{~mW})$, PEG8000 molecules (6 \%) were depleted away from the hot center to cooler surroundings upon their intrinsic thermophoresis, leading to a steady PEG8000 concentration ( $\left.c_{P E G}\right)$ distribution until the PEG8000 flux induced by thermophoresis was balanced by Brownian diffusion:

$J_{P E G}=-D_{P E G} \nabla c_{P E G}-c_{P E G} S_{T}^{P E G} D_{P E G} \nabla T=0$

The spatial distribution of PEG8000 was determined based on the experimental 
measurement of $S_{T}^{P E G}\left(0.04 \mathrm{~K}^{-1}\right.$, see Measurement of $S_{T}$ for PEG8000) and finite element simulation (see Numerical simulation of thermophoretic accumulation of viral particles). The simulation results revealed that only $2.4 \%$ of PEG was retained at the hot center after thermophoresis, indicating that $60 \%$ of PEG molecules were expelled based on the original PEG concentration of $6 \%$ (Figure S3).

Effective Soret coefficient $S_{T}^{*}$ of viral particles. Suspending in this PEG8000 concentration gradient, the viral particles exhibited an effective thermophoresis $\left(S_{T}^{*}\right)$ arising from the superimposition of two effects, intrinsic thermophoresis of viral particles $\left(S_{T}^{\text {Virus }}\right)$ and diffusiophoresis of viral particles $\left(S_{T}^{D}\right)$ towards the low PEG8000 concentration (hot center) upon the entropy depletion interaction between viral particles and PEG8000 molecules.

$$
S_{T}^{*}=S_{T}^{\text {Virus }}+S_{T}^{D}=S_{T}^{\text {Virus }}-2 \pi\left(S_{T}^{P E G}-\frac{1}{T}\right) a \delta^{2} c_{P E G}^{0}
$$

We note that the $S_{T}^{\text {Virus }}$ can be negligible due to the presence of a large amount of surface proteins that decrease the net surface charge. Owing to the high PEG8000 concentration to provide strong repulsive force, the $S_{T}^{D}$ dominated over the $S_{T}^{\text {Virus }}$ and Equation (4) can be simplified as

$$
S_{T}^{*}=S_{T}^{D}=2 \pi\left(S_{T}^{P E G}-\frac{1}{T}\right) a \delta^{2} c_{0}^{P E G}
$$

Therefore, viral particles can be accumulated at the hot center by this PEG-enhanced thermophoresis, resulting in a high local virus concentration $\left(c_{\text {Virus }}\right)$ 
determined by the counterbalance between thermophoresis and Brownian diffusion:

$$
\frac{\mathrm{D} c_{\text {Virus }}}{\mathrm{D} t}=\nabla \cdot\left(-D_{\text {Virus }} \nabla c_{\text {Virus }}-c_{\text {Virus }} S_{T}^{*} D_{\text {Virus }} \nabla T\right)
$$

This equation was solved by finite element simulation and obtained an enrichment fold of 2100 for viral particles within 15 min laser irradiation (see Numerical simulation of thermophoretic accumulation of viral particles).

Fabrication of the 80 - $\mu$ m-high microchamber. The 80 - $\mu$ m-high microchamber was fabricated by sandwiching a layer of $80 \mu \mathrm{m}$ double-sided tape (containing a 7 mm-diameter punched hole) between a sapphire top slide and a glass bottom slide. The sapphire top slide and the glass bottom slide were both $1 \mathrm{~mm}$ thick.

Thermophoretic accumulation of viral particles. Len was chosen as model particles to test the feasibility of thermophoretic accumulation. Before thermophoretic enrichment, $50 \mu \mathrm{L}$ of Len $\left(10^{4} \mathrm{TU} \mu \mathrm{L}^{-1}\right)$ was stained with $5 \mu \mathrm{L}$ of 1 $\mu \mathrm{M}$ DiI at $37{ }^{\circ} \mathrm{C}$ for $15 \mathrm{~min}$. For optimization of PEG concentration, $2.75 \mu \mathrm{L}$ of stained Len solution was mixed with $0 \mu \mathrm{L}, 0.5 \mu \mathrm{L}, 1 \mu \mathrm{L}$, and $1.5 \mu \mathrm{L}$ of $30 \%$ PEG8000 solution, respectively, and added with PBS to reach a fixed total volume of $5 \mu \mathrm{L}$, which resulted in a final concentration of PEG8000 of $0 \%, 3 \%, 6 \%$, and $9 \%$, respectively. Then $4 \mu \mathrm{L}$ of the mixture was subjected into the 80 - $\mu \mathrm{m}$-high microchamber. The microchamber was placed on an inverted fluorescence microscope (Nikon, Japan). The thermophoretic accumulation was achieved by focusing an infrared laser $(1480 \mathrm{~nm}, 15 \mathrm{~mW}$, Changchun Laser Optoelectronics 
Technology, China) on the glass slide for $15 \mathrm{~min}$ irradiation. The pictures before and after laser irradiation were captured by a $40 \times$ objective and an electron multiplying CCD (EMCCD, Andor, England) with a $2 \times 2$ pixels binning. The exposure time was $50 \mathrm{~ms}$ and the gain was 15 . Each measurement was taken from three distinct samples.

Optimization of PEG molecular weight. $50 \mu \mathrm{L}$ of lentivirus (Len) particles $\left(10^{4}\right.$ TU $\mu \mathrm{L}^{-1}$ ) were stained with $5 \mu \mathrm{L}$ of $1 \mu \mathrm{M}$ DiI at $37{ }^{\circ} \mathrm{C}$ for $15 \mathrm{~min}$, suspended in $6 \%$ solutions of PEG with different molecular weights (4000 Da, 6000 Da, 8000 $\mathrm{Da}$, and $10000 \mathrm{Da}$ ), and subjected to thermophoretic accumulation for $15 \mathrm{~min}$. The optimal molecular weight of PEG was determined to be $8000 \mathrm{Da}$, at which the fluorescence signal of DiI-labeled viral particles reached a maximum value and did not significantly increase for a higher PEG molecular weight (Figure S5).

Transmission electron microscopy (TEM). To observe the morphology of the Len and PSV, $5 \mu \mathrm{L}$ of Len solution $\left(10^{5} \mathrm{TU} \mu \mathrm{L}^{-1}\right)$ or PSV solution $\left(3 \times 10^{4} \mathrm{TU}_{\mu \mathrm{L}^{-1}}\right)$ was dropped on the Formvar/carbon-coated copper grid. After drying, the samples were stained with $1 \%$ uranyl acetate for 5 times and blotted with filter paper. A Tecnai G2 20 S-TWIN TEM (FEI, USA) was used for the sample observation.

Colocalization analysis of PSV. PSV solution $\left(15 \mu \mathrm{L}, 10^{4} \mathrm{TU} \mu \mathrm{L}^{-1}\right)$ was incubated with DiI solution $(1.5 \mu \mathrm{L}, 1 \mu \mathrm{M})$ at $37{ }^{\circ} \mathrm{C}$ for $15 \mathrm{~min}$. Then the DiI-labeled PSV 
was mixed with $6 \mu \mathrm{L}$ of $\mathrm{MgCl}_{2}(10 \mathrm{mM}), 3 \mu \mathrm{L}$ of Cy5-labeled aptamer (Cy5-Aptamer, $100 \mathrm{nM}$ ), and $4.5 \mu \mathrm{L}$ of PBS. The solution was then transferred into the microchamber and observed on an inverted fluorescence microscope (Nikon, Japan).

One-step thermophoretic detection of PSV. PSV solution $\left(2.5 \mu \mathrm{L}, 10^{4} \mathrm{TU} \mu \mathrm{L}^{-1}\right)$ was mixed with $\mathrm{MgCl}_{2}(1 \mu \mathrm{L}, 10 \mathrm{mM})$, Cy5-Aptamer $(0.5 \mu \mathrm{L}, 100 \mathrm{nM})$, and PEG8000 solution $(1 \mu \mathrm{L}, 30 \%)$. Then $4 \mu \mathrm{L}$ of the mixture was immediately transferred into an $80-\mu \mathrm{m}$-high microchamber and the microchamber was placed on the inverted fluorescence microscope (Nikon, Japan). An infrared laser (1480 nm, $15 \mathrm{~mW}$, Changchun Laser Optoelectronics Technology, China) was focused into the center of the microchamber for thermophoretic accumulation of PSV, along with the simultaneous aptamer labeling of PSV. To confirm the accumulation of aptamer-labeled PSV, the pictures were continuously captured with 5 min interval by a $40 \times$ objective and an electron multiplying CCD (EMCCD, Andor, England) with a $2 \times 2$ pixels binning. The exposure time was $50 \mathrm{~ms}$ and the gain was 15 . The experiment was repeated three times independently.

To test the sensitivity of the thermophoretic detection, $2.5 \mu \mathrm{L}$ of PSV solution with different concentrations $\left(0,6.25 \times 10^{2}, 1.25 \times 10^{3}, 2.5 \times 10^{3}, 5 \times 10^{3}\right.$, and $10^{4} \mathrm{TU}$ $\left.\mu \mathrm{L}^{-1}\right)$ was mixed with $\mathrm{MgCl}_{2}(1 \mu \mathrm{L}, 10 \mathrm{mM})$, Cy5-Aptamer $(0.5 \mu \mathrm{L}, 100 \mathrm{nM})$, and PEG8000 solution (1 $\mu \mathrm{L}, 30 \%)$. The samples were then applied for the thermophoretic detection. Measurement for each concentration was taken from 
three distinct samples.

To demonstrate the specificity of the thermophoretic detection, PSV solution $\left(2.5 \mu \mathrm{L}, 10^{4} \mathrm{TU} \mu \mathrm{L}^{-1}\right)$ or Len solution $\left(2.5 \mu \mathrm{L}, 10^{4} \mathrm{TU} \mu \mathrm{L}^{-1}\right)$ were mixed with Cy5-Aptamer solution $(0.5 \mu \mathrm{L}, 100 \mathrm{nM})$ or Cy5-Rdm solution $(0.5 \mu \mathrm{L}, 100 \mathrm{nM})$ respectively, followed by adding $\mathrm{MgCl}_{2}(1 \mu \mathrm{L}, 10 \mathrm{mM})$ and PEG8000 solution (1 $\mu \mathrm{L}, 30 \%$ ). Each measurement was taken from three distinct samples.

Thermophoretic detection of spiked PSV in swab samples. The oropharyngeal swab sample was from 22 healthy volunteers. We spiked PSV into the swab sample with different final concentrations ranging from 500 to $5000 \mathrm{TU} \mu \mathrm{L}^{-1}$ as positive swab samples. We also spiked Len into 7 randomly-selected healthy swab samples with different final concentrations ranging from 500 to $5000 \mathrm{TU} \mu \mathrm{L}^{-1}$. Healthy swab samples and Len-spiked healthy swab samples were used as negative swab samples. The threshold value was determined as $2.4 \times 10^{5}$ based on the maximized accuracy $(100 \%)$ for the discrimination between positive samples $(n=22)$ and negative samples $(n=29)$. The information of all the swab samples was summarized in Table S2.

Enzyme-linked immunosorbent assay (ELISA). Oropharyngeal swab samples $(100 \mu \mathrm{L})$ containing different concentrations of PSV (500 TU $\mu \mathrm{L}^{-1}, 1000 \mathrm{TU} \mu \mathrm{L}^{-1}$, $2000 \mathrm{TU} \mu \mathrm{L}^{-1}$, and $5000 \mathrm{TU} \mu \mathrm{L}^{-1}$ ) were added to ELISA plates (3 wells for each concentration) modified with spike protein antibody and incubated at room 
temperature for $2 \mathrm{~h}$. Samples were then removed and each well was washed by washing buffer for 3 times. Subsequently $100 \mu \mathrm{L}$ HRP-conjugated spike protein antibody was added to each well. After incubation at room temperature for $1 \mathrm{~h}$, the antibody solution was removed and each well was washed by washing buffer for 3 times. Plates were developed with tetramethylbenzidine for $20 \mathrm{~min}$ and stopped with stopping buffer. The plates were read at $450 \mathrm{~nm}$ with a microplate reader (Synergy H1, Biotek, USA). A standard curve was established using spike protein standard with different concentrations up to $10^{4} \mathrm{pg} \mathrm{mL}^{-1}$. The LoD of ELISA was determined as $2530 \mathrm{TU} \mu \mathrm{L}^{-1}$ of PSV based on the $3 \times$ standard deviation above the blank. Hence, only the swab samples with the highest PSV concentration of 5000 TU $\mu \mathrm{L}^{-1}$ were detectable by ELISA (Figure S11). 


\section{Supplementary Tables}

Table S1. Summary of sequences.

\begin{tabular}{cl}
\hline Sequence name & \multicolumn{1}{c}{ Sequence (5'-3') } \\
\hline Cy5-Aptamer & Cy5-ATCCAGAGTGACGCAGCATTTCATCGGGTCCAAAAGG \\
& GGCTGCTCGGGATTGCGGATATGGACACGT \\
Cy5-Rdm & Cy5-CAAGGAATAGGGGTCGGTGTGGGTGGTTATGATTGGC \\
& TTCCTTG \\
\hline
\end{tabular}


Table S2. Information of the spiked swab samples.

\begin{tabular}{|c|c|c|c|c|c|c|c|}
\hline $\begin{array}{c}\text { Sample } \\
\text { No. } \\
\end{array}$ & $\begin{array}{c}\text { Volunteer } \\
\text { No. }\end{array}$ & $\begin{array}{c}\text { PSV } \\
\left(\mathrm{TU} \mu \mathrm{L}^{-1}\right)\end{array}$ & $\begin{array}{c}\text { Len } \\
\left(\mathrm{TU} \mu \mathrm{L}^{-1}\right)\end{array}$ & $\begin{array}{c}\text { Sample } \\
\text { No. } \\
\end{array}$ & $\begin{array}{c}\text { Volunteer } \\
\text { No. }\end{array}$ & $\begin{array}{c}\text { PSV } \\
\left(\mathrm{TU} \mu \mathrm{L}^{-1}\right)\end{array}$ & $\begin{array}{c}\text { Len } \\
\left(\mathrm{TU} \mu \mathrm{L}^{-1}\right)\end{array}$ \\
\hline Positive & & & & 26 & 4 & 1 & 1 \\
\hline 1 & 1 & 5000 & 1 & 27 & 5 & 1 & 1 \\
\hline 2 & 2 & 5000 & I & 28 & 6 & 1 & I \\
\hline 3 & 3 & 4000 & 1 & 29 & 7 & 1 & 1 \\
\hline 4 & 4 & 2500 & 1 & 30 & 8 & 1 & 1 \\
\hline 5 & 5 & 2000 & 1 & 31 & 9 & 1 & I \\
\hline 6 & 6 & 2000 & 1 & 32 & 10 & 1 & 1 \\
\hline 7 & 7 & 2000 & 1 & 33 & 11 & 1 & 1 \\
\hline 8 & 8 & 2000 & 1 & 34 & 12 & 1 & 1 \\
\hline 9 & 9 & 1500 & I & 35 & 13 & 1 & 1 \\
\hline 10 & 10 & 1500 & I & 36 & 14 & 1 & I \\
\hline 11 & 11 & 1500 & I & 37 & 15 & I & I \\
\hline 12 & 12 & 1000 & 1 & 38 & 16 & 1 & 1 \\
\hline 13 & 13 & 1000 & 1 & 39 & 17 & 1 & 1 \\
\hline 14 & 14 & 1000 & I & 40 & 18 & I & I \\
\hline 15 & 15 & 1000 & I & 41 & 19 & 1 & I \\
\hline 16 & 16 & 1000 & I & 42 & 20 & I & I \\
\hline 17 & 17 & 800 & 1 & 43 & 21 & 1 & 1 \\
\hline 18 & 18 & 800 & l & 44 & 22 & 1 & I \\
\hline 19 & 19 & 800 & 1 & Len & & & \\
\hline 20 & 20 & 500 & I & 45 & 7 & 1 & 5000 \\
\hline 21 & 21 & 500 & I & 46 & 21 & 1 & 2500 \\
\hline 22 & 22 & 500 & I & 47 & 1 & 1 & 2000 \\
\hline Healthy & & & & 48 & 6 & I & 1500 \\
\hline 23 & 1 & / & 1 & 49 & 11 & I & 1000 \\
\hline 24 & 2 & 1 & 1 & 50 & 20 & 1 & 800 \\
\hline 25 & 3 & 1 & I & 51 & 13 & 1 & 500 \\
\hline
\end{tabular}


Table S3. The cost of the one-step thermophoretic assay for detection of SARS-CoV-2 in one sample.

\begin{tabular}{cccc}
\hline $\begin{array}{c}\text { Reagents and } \\
\text { material }\end{array}$ & Quantity & Unit price & Cost \\
\hline Aptamer & 1 pmol & $0.006 \$$ pmol$^{-1}$ & $0.006 \$$ \\
Glass slide & 1 & $0.03 \$$ & $0.03 \$$ \\
Sapphire slide & 1 & $0.3 \$$ & $0.3 \$$ \\
Pipette tip & 5 & $0.01 \$$ & $0.05 \$$ \\
Total & & & $\sim 0.4 \$$ \\
\hline
\end{tabular}




\section{Supplementary Figures}

a

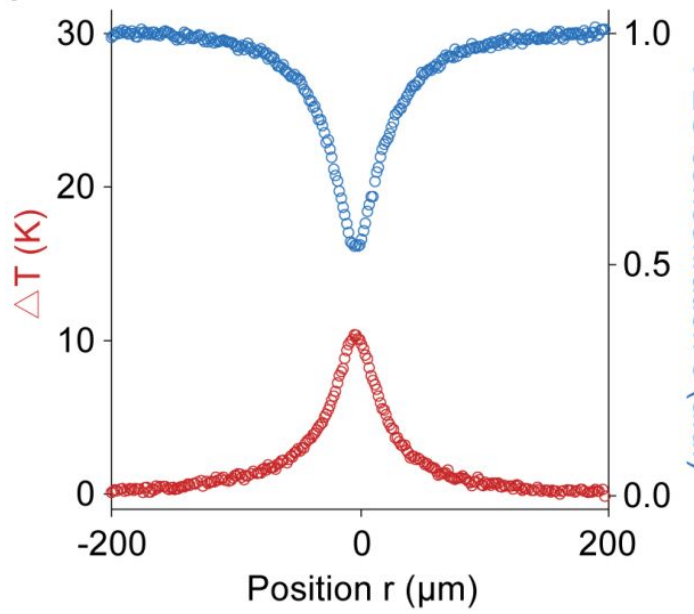

b

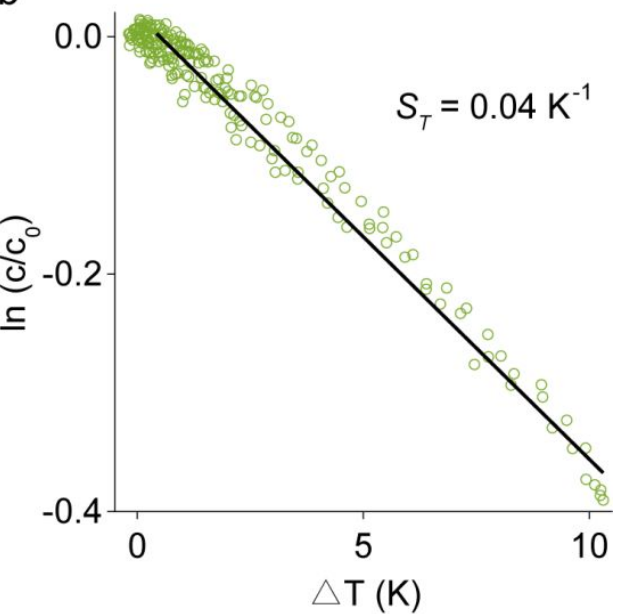

Figure S1. Measurement of $S_{T}$ for PEG8000. (a) Temperature distribution and concentration distribution of the PEG8000 as a function of radical position $r$ from the center of laser focus in the $15-\mu \mathrm{m}$-high microchamber. (b) $S_{T}$ determined as the slope of linear relationship between PEG8000 concentration and temperature rise. 


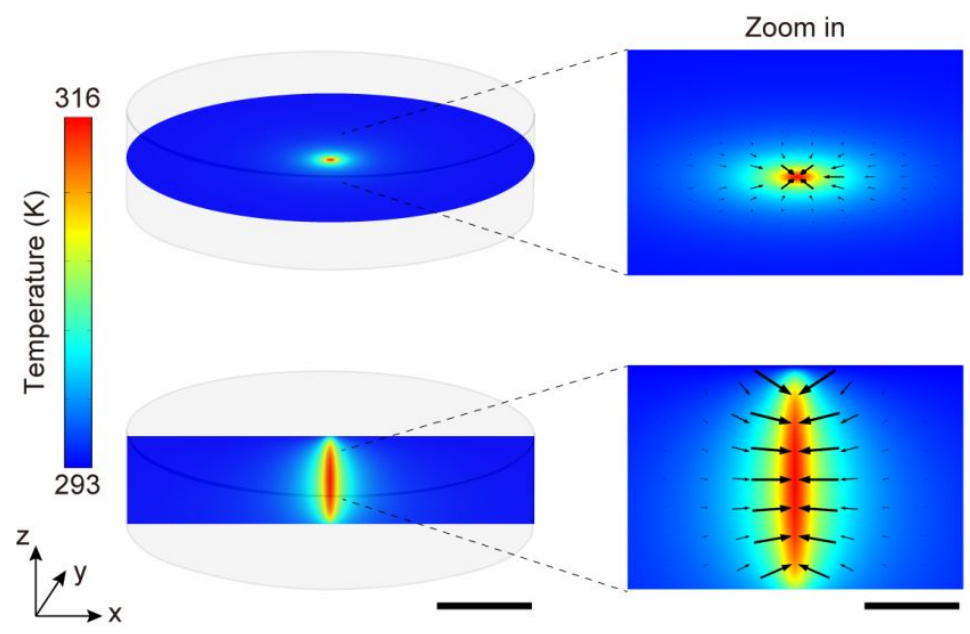

Figure S2. Numerical simulation of the spatial distribution of temperature and the temperature gradient (black arrows) at the laser spot center. Scale bar, $80 \mu \mathrm{m}$ (zoom in, $30 \mu \mathrm{m})$. 


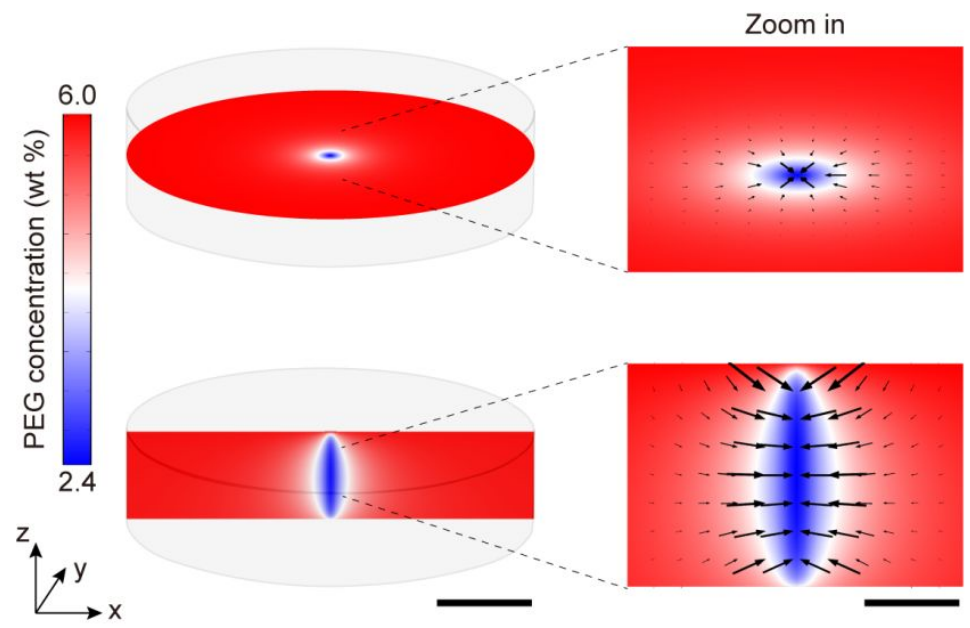

Figure S3. Numerical simulation of the spatial distribution of PEG8000 and the gradient of PEG8000 concentration (black arrows) at the laser spot center. Scale bar, $80 \mu \mathrm{m}$ (zoom in, $30 \mu \mathrm{m})$. 


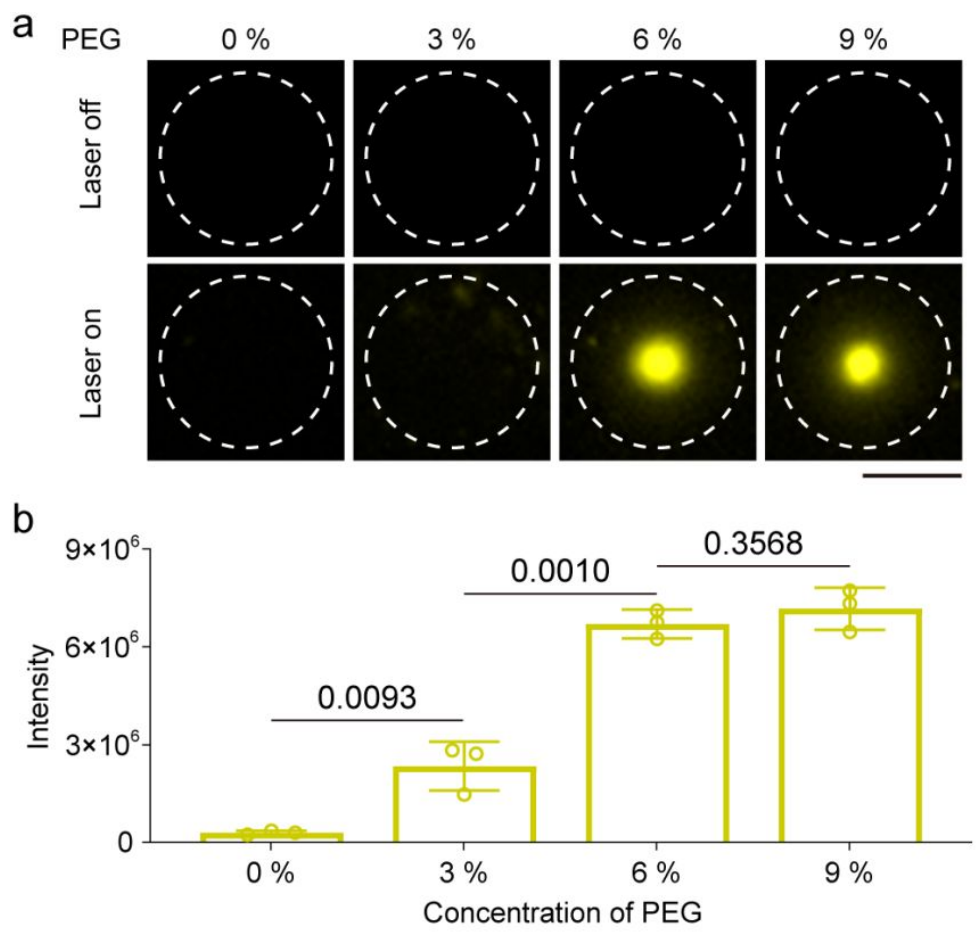

Figure S4. Optimization of PEG8000 concentration for thermophoretic accumulation.

(a) Fluorescence images of accumulated DiI-labeled Len after PEG-enhanced thermophoretic accumulation with different PEG8000 concentration. Scale bar, 20 $\mu \mathrm{m}$. (b) The relationship between fluorescence intensity and PEG8000 concentration $(n=3$, mean \pm s.d. $)$. 


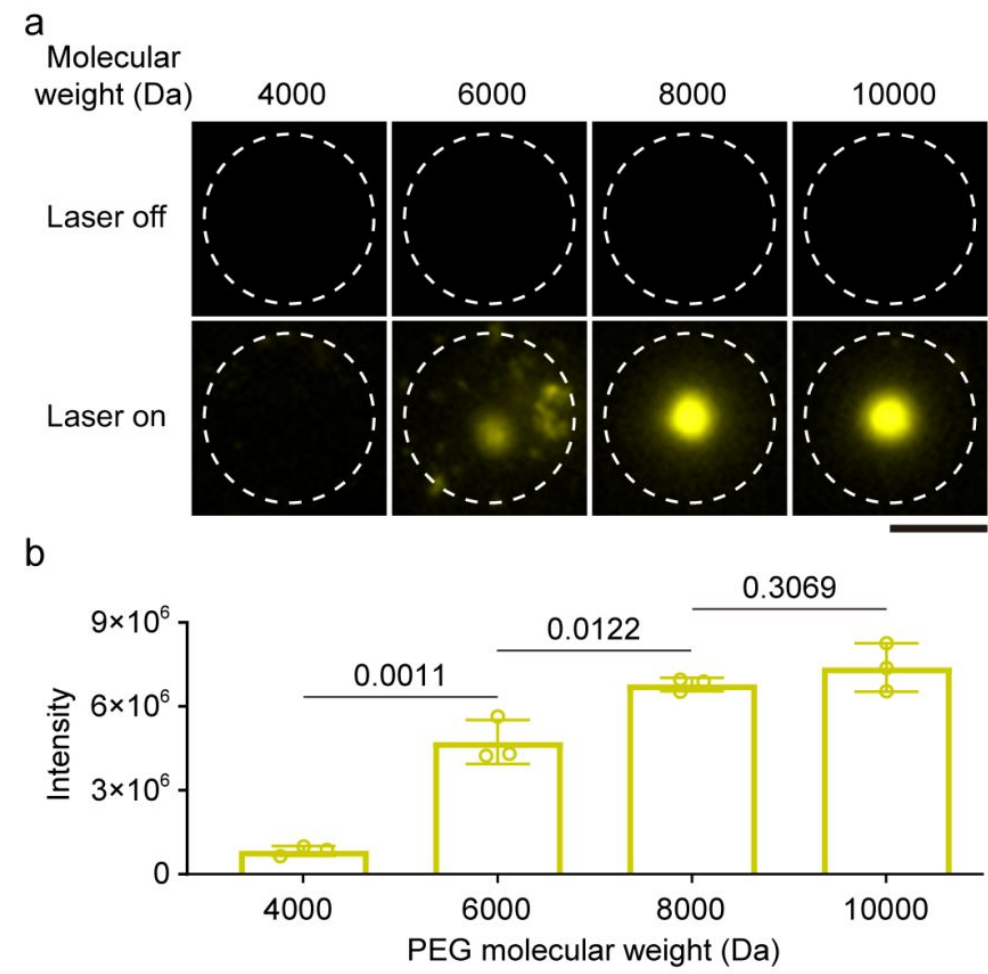

Figure S5. Effect of PEG molecular weight on thermophoretic accumulation of viral particles. (a) Fluorescence images accumulated DiI-labeled Len after PEG-enhanced thermophoretic accumulation with different PEG molecular weights ranging from 4000 to $10000 \mathrm{Da}$ at a concentration of $6 \%$. Scale bar, $20 \mu \mathrm{m}$. (b) The relationship between fluorescence intensity and PEG molecular weight $(n=3$, mean \pm s.d.). 

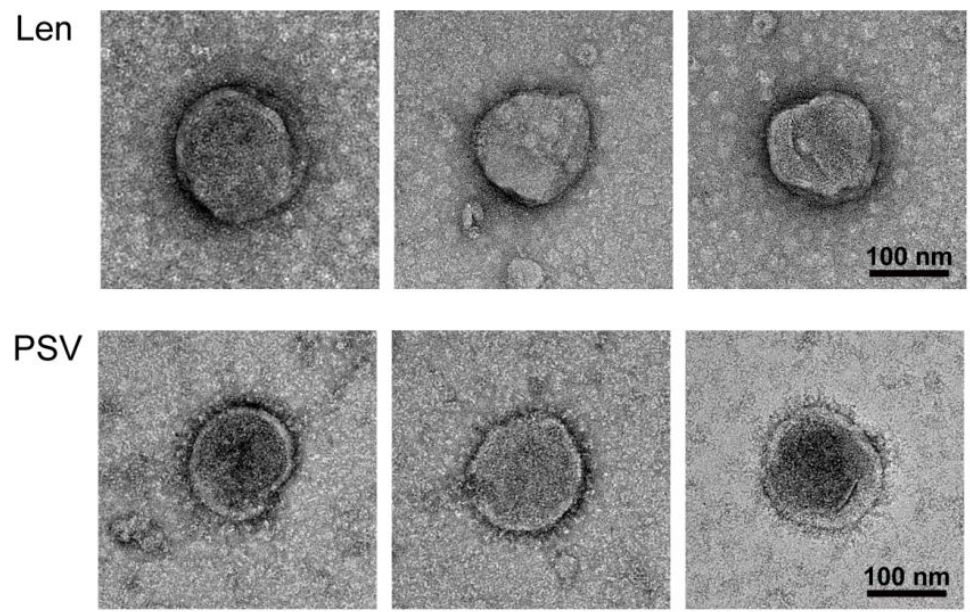

Figure S6. TEM images of Len and SARS-CoV-2 PSV. 

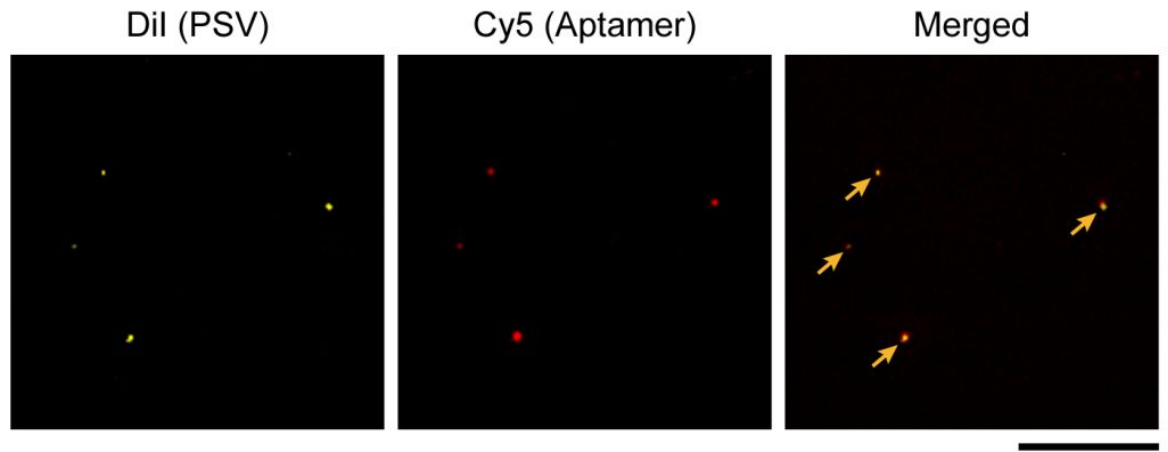

Figure S7. Colocalization analysis of DiI-labeled PSV and Cy5-Aptamer. Scale bar, $50 \mu \mathrm{m}$. 


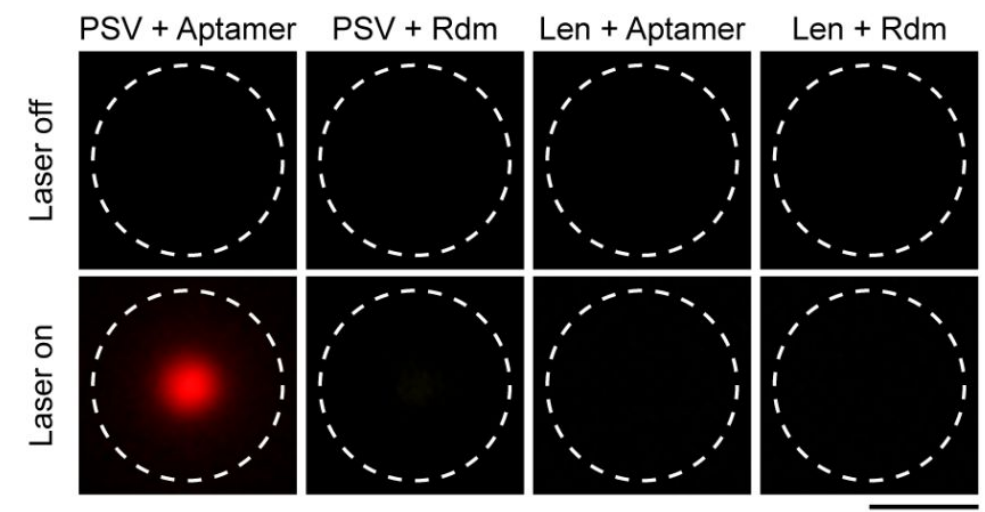

Figure S8. Fluorescence images of the accumulated PSV or Len labeled with Cy5-Aptamer or Cy5-Rdm sequence. Scale bar, $20 \mu \mathrm{m}$. 


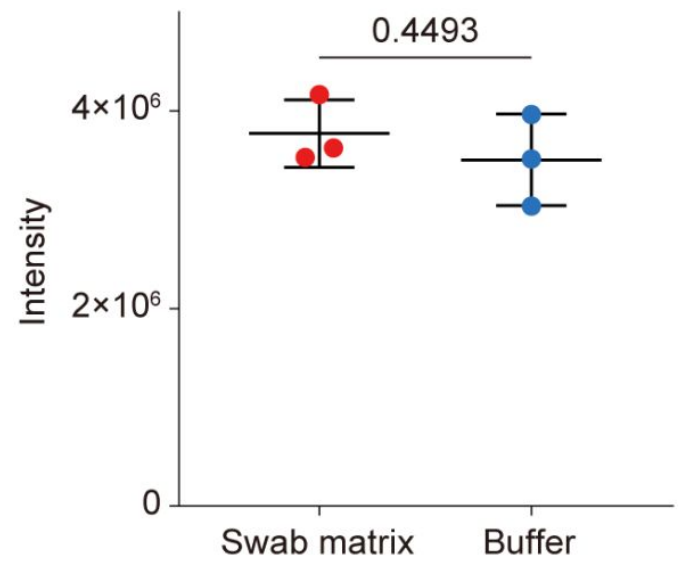

Figure S9. Fluorescence intensities from swab samples (containing $5000 \mathrm{TU} \mu \mathrm{L}^{-1}$ of PSV) and buffer (containing $5000 \mathrm{TU} \mu \mathrm{L}^{-1}$ of PSV) detected by aptamer-based thermophoretic assay ( $n=3$, mean \pm s.d.). 


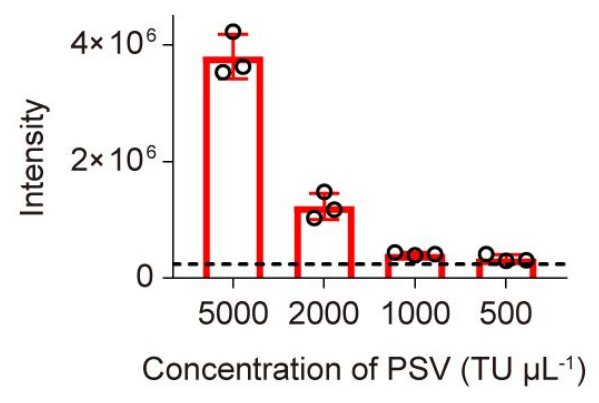

Figure S10. Evaluation of aptamer-based thermophoretic assay for detecting oropharyngeal swab samples. Fluorescence intensity of positive swab samples containing different concentrations of PSV (500 TU $\mu \mathrm{L}^{-1}, 1000 \mathrm{TU} \mu \mathrm{L}^{-1}, 2000 \mathrm{TU}$ $\mu \mathrm{L}^{-1}$, and $\left.5000 \mathrm{TU} \mu \mathrm{L}^{-1}\right)$ upon 15 -min laser heating ( $n=3$, mean \pm s.d.). Dashed line indicates the threshold value of $2.4 \times 10^{5}$. 


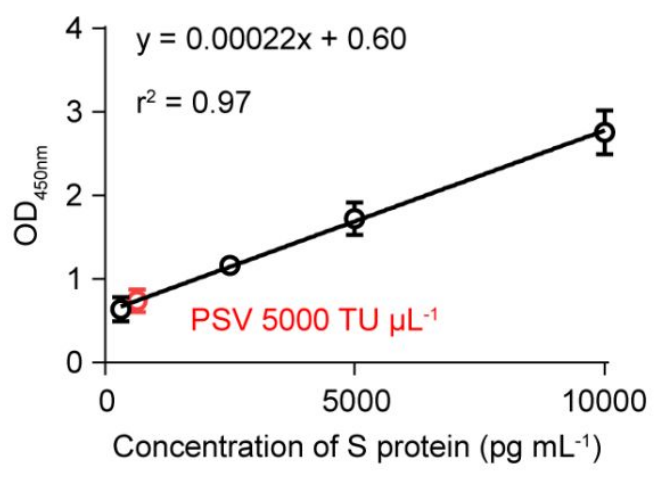

Figure S11. Standard curve for determining the sensitivity of ELISA for PSV detection in oropharyngeal swab samples $(n=3$, mean \pm s.d.). The red dot indicates swab sample containing $5000 \mathrm{TU} \mu \mathrm{L}^{-1}$ of PSV. 


\section{References}

S1 Sun, M.; Liu, S.; Wei, X.; Wan, S.; Huang, M.; Song, T.; Lu, Y.; Weng, X.; Lin, Z.; Chen, H.; Song, Y.; Yang, C., Aptamer Blocking Strategy Inhibits SARS-CoV-2 Virus Infection. Angew. Chem. Int. Edit. 2021, 60, DOI: 10.1002/anie.202100225.

S2 Ou, X.; Liu, Y.; Lei, X.; Li, P.; Mi, D.; Ren, L.; Guo, L.; Guo, R.; Chen, T.; Hu, J.; Xiang, Z.; Mu, Z.; Chen, X.; Chen, J.; Hu, K.; Jin, Q.; Wang, J.; Qian, Z., Characterization of spike glycoprotein of SARS-CoV-2 on virus entry and its immune cross-reactivity with SARS-CoV. Nat. Commun. 2020, 11, 1620. 